\title{
Teaching Information Technology to a non-Technical Audience: Graduate Course on IT for the Historical Profession
}

\author{
Shawn A. Ross \\ William Paterson University, Wayne, New Jersey, USA
}

\author{
RossS@wpunj.edu
}

\begin{abstract}
The graduate program in History at William Paterson University explicitly promotes itself as emphasizing information technology. HIST501: Information Technology for the Historical Profession, a course required of all entering graduate students, serves as a foundation for the IT literacy the program seeks to foster. Teaching HIST501 has proved challenging, however, due to the diverse interests and backgrounds of our students and a lack of integration with the broader graduate program. By structuring the course around an historical project_-research, composition, and presentation of a thesis proposalstudents immediately realize the relevance of IT to their research and teaching. Students learn IT applications and tools by using them to advance their proposal. By devoting class time to discussion of techniques for solving problems, while students learn the details of particular software packages on their own or through individual tutoring, a wide range of skill levels can be accommodated.
\end{abstract}

Keywords : Information technology curricula, information technologies for the humanities, information technology and history

\section{Introduction}

The graduate program in History at William Paterson University explicitly promotes itself as emphasizing information technology. HIST501: Information Technology for the Historical Profession, a course required of all entering graduate students, serves as a foundation for the IT literacy the program seeks to foster. Because of the diverse interests and widely varying IT experience among students, teaching HIST501 has proved challenging, a problem exacerbated by a lack of integration of this course with the broader graduate program. Recent changes in the course, however, have dramatically improved student learning and satisfaction. This paper represents a preliminary report on the restructuring of the course. The revised course replaces out-of-context, rote learning of hardware and software with a coherent project: research, composition, and presentation leading to a thesis proposal and systematic plan for further research. Students learn IT applications, tools, and techniques as they complete this project, which also demonstrates the relevance of IT to their research and teaching. By devoting class time to discussion of how information technology can help students solve the problems that arise as students prepare a thesis proposal-while students learn the details of particular software packages on their own or through ind i-

Material published as part of these proceedings, either on-line or in print, is copyrighted by Informing Science. Permission to make digital or paper copy of part or all of these works for personal or classroom use is granted without fee provided that the copies are not made or distributed for profit or commercial advantage AND that copies 1) bear this notice in full and 2) give the full citation on the first page. It is permissible to abstract these works so long as credit is given. To copy in all other cases or to republish or to post on a server or to redistribute to lists requires specific permission from the publisher at Publisher@InformingScience.org vidual tutoring - a wide range of skill levels can be accommodated and minimum proficiencies can be attained by even the least experienced students. Changes made to HIST501 have dramatically improved student satisfaction with the course, have made it more enjoyable to teach, and have helped students learn to be independent and critical users of information technology. 


\section{Institutional Setting}

William Paterson University is a comprehensive, masters-granting, regional institution serving, primarily, northeastern New Jersey. In 1999 the Department of History at William Paterson University initiated a Masters of Arts degree, which currently enrolls approximately 20 students. This program seeks to integrate the use of information technology in research and teaching into a broad, globally-oriented curriculum that culminates with the completion of a thesis based upon original research. Although every course in the program incorporates an information technology component, one of the first classes all incoming graduate students take is a required course entitled HIST501 Information Technology for the Historical Profession.

\section{Student Profile}

Our graduate program enrolls a diverse group of students. Some choose the program because of its emphasis on information technology, but many come to William Paterson University for other reasons: the reputation of particular faculty members, the availability of evening courses, or convenience of location, for example. Although the History graduate program strives to meet the needs of students who plan to pursue a Ph.D. after completion of their Master's degree, many of our graduate students are primary and secondary teachers seeking a terminal M.A., while others have returned to school simply out of interest in the subject and a desire for personal enrichment. Finally, in addition to having varying needs and levels of interest with respect to information technology, entrance surveys indicate that students begin the program - and enroll in HIST501—with widely divergent IT backgrounds. While some incoming graduate students are already familiar with a wide variety of applications and techniques, others are complete no vices.

In short, challenges are posed by the wide range of students' expertise and enthusiasm and the need to cater to educators earning a terminal master's degree while not ignoring the interests of graduate students who may be going on to a doctoral program.

\section{Goals and problems}

\section{Course Goals}

As the only explicitly IT-oriented course in a graduate program billed as emphasizing IT and its applicability to the teaching and research expected of profe ssional historians and history educators, a significant burden is placed on HIST501. The course must introduce students to the skills required to undertake a Master's degree with an integrated IT component. HIST501 must also prepare students to produce a thesis involving original research, present the results of that thesis to faculty and fellow graduate students, and prepare it for online publication. Finally, the course should impart IT literacy, facilitating the continuing success of both educators seeking a terminal Master's degree and students planning on pursuing the Ph.D. To accomplish these broader goals, the Department of History has established three more specific objectives for the course:

- To teach students the application of information technology to historical research and teaching.

- To acquaint students with the basics of quantitative analysis.

- To help students develop the ability to produce effective electronic multimedia presentations (including both online and live presentations).

Of particular interest to the department is the preparation of primary and secondary teachers, who constitute a significant portion of our graduate students. The state of New Jersey has set out ambitious goals regarding information technology proficiency among its educators, regardless of their discipline or the level at which they teach. These goals include insuring "at a minimum, intermediate proficiency levels 
in utilizing educational technology to enhance student achievement" and universal utilization of "technology tools and applications that provide opportunities for authentic, student-centered, project-based learning" (Working towards the Future with Our Children: The Education Technology Plan for New Jersey, 2002). Nationwide, the lack of teacher training remains a major obstacle to implementing technology in the classroom (Soner Yildirim, 2000). The faculty of the Department of History at William Paterson Unive rsity therefore believe that we have an important role to play in ensuring that educators who complete our program meet and surpass the rising information technology expectations of the state of New Jersey. HIST501, as the sole required course devoted to information technology, bears much of the burden for meeting these goals.

Overall, HIST501 initiates the process of familiarizing students with a variety of IT applications in their teaching and research and, ideally, facilitates students' ability to seek out and learn new technology tools independently.

\section{Problems}

Earlier incarnations of HIST501 focused on teaching the use of specific hardware and software. Wide variation in level of competence complicated teaching; more IT- literate students reported being bored much of the time, while less advanced students complained being lost or overwhelmed (Soner Yildirim, 2000). Furthermore, little connected one class session with another, or HIST501 with the broader graduate curriculum. Discussions with students and faculty indicate a great deal of frustration among all involved. Too much of the course was dedicated to rote learning of applications rather than the ability to use technology to solve problems (Information Literacy: Competency Standards for Higher Education, 2001; Abby Kasowitz-Scheer and Michael Pasqualoni, 2002). Few students saw the relevance of HIST501 to their course of study or to their career goals. Faculty have been disappointed by advanced graduate students' low proficiency with and unwillingness to use information technology that should have been familiar from HIST501. Everyone involved hoped that students would master a wide range of IT applications, tools, and techniques; most were disappointed.

\section{The Revised Course}

\section{Revisions to HIST501}

The remainder of this paper constitutes a preliminary report about changes I have made in this course over the past year, during which I have taught HIST501 twice. I believe that such a report, despite the early stage of the revision of the course, is warranted as these changes have led to a greatly increased student satisfaction and more effecting acquisition of technological literacy. The structure, use of class time, and assignments for the course have all been extensively modified in an attempt to replace "computer literacy," the rote learning of specific hardware and software, with "fluency with technology," defined as "understanding the underlying concepts of technology and applying problem solving and crit ical thinking to using technology" (Information Literacy: Competency Standards for Higher Education, 2001).

In order to foster informed use of information technology to solve problems, the litany of unrelated, hardware- and software-centered assignments was replaced with a project pursued by the student throughout the semester (Abby Kasowitz-Scheer and Michael Pasqualoni, 2002). The revised course now focuses on the production of a thesis proposal and plan of research. On the first day of class, students are given the official department guidelines for both the formal proposal and the finished thesis. Students spend the rest of the semester developing their proposals, and IT literacy is presented in a way that compliments the stages of this development: 
- Research. Many of our students do not effectively use IT effectively in their research, a problem not limited to William Paterson University (Information Literacy: Competency Standards for Higher Education, 2001; Abby Kasowitz-Scheer and Michael Pasqualoni, 2002; Virginia Massey-Burzio, 1999). Approximately the first third of the semester is spent on learning to acquire information. This section includes training in the use of library databases (provided in large part by library staff), the digitization of physical material (digital photography, audio recording, and video), and the acquisition of electronic and traditional primary source documents. By the end of this section of the course students have a good idea of the primary and secondary sources available for their project and are well on their way to developing a bibliography and research plan.

- Organization and manipulation of information. The next section of HIST501 is devoted to storing, organizing, and manipulating information (including bibliographical software, spreadsheets, relational databases, and statistical software). An introduction to statistics and quantitative approaches to history is also provided.

- Online and live presentation. During the final third of the course students develop their ability to present the results of their research, in print, in person, and online. The details of using particular hardware or software applications are learned as necessary; such topics as image manipulation and sound editing arise organically as students begin constructing websites and composing presentations. Students spend the final weeks of class critiquing each others' web sites and presentations, mutually solving specific problems.

Figure 1 (at end of paper) contains a sample syllabus for HIST501 from Spring Semester 2003.

In addition to changes in the structure of the course, use of class time has also been refocused. Instead of the teaching of a particular piece of hardware or software each meeting, class now revolves around a question: what IT tools are available to help accomplish a particular task related to historical research or presentation? The capabilities and limitations of a particular application, Adobe Photoshop or Microsoft Access for example, are then discussed, along with any necessary concepts, such as image compression or the nature of a relational database. If the application is particularly complicated, class may include a brief introduction to the software, but in general novices are asked to take free workshops offered by William Paterson University Instruction and Research Technologies (IRT) on their own time, or come to arrange for personal instruction from me. The remainder of class, as well as the assignment for the following week, explores use of the tools or applications in question to advance the thesis proposal.

Finally, I have brought student assignments into line with these modifications. Students submit their thesis proposals, websites, and in-class presentations for critique by me and by their peers. Students also keep a journal detailing the process of developing their thesis proposals, as well as construc tion of the ir websites and presentations. As an interim step, this year I have also given an exit examination over more specific IT skills to evaluate the effectiveness of changes to the course. Overall, students displayed much stronger outcomes as well as improved satisfaction with the course. Please refer to Figure 2 (at end of paper) for detailed assignment instructions distributed to students Spring Semester 2003.

\section{Benefits of the Revision}

Organizing HIST501 around the development of a thesis proposal has proven to be far more effective than earlier arrangements. Applications and tools are learned through their use in advancing a specific historical project: development and presentation of a viable thesis proposal. From the first day of class, when students are given the official departmental thesis proposal guidelines as part of their assignment, the course explicitly conveys to students the relevance of information technology to their historical inquiry in general and their own graduate work in particular. 
Structuring class time around solving problems related to the production of a thesis proposal also addresses the range of abilities represented among students, since most class time is devoted to nontechnical discussion of what applications or tools are useful for specific purposes and why - a conversation that even technologically inexperienced students can usually join. Such discussions alert students to available IT tools, introduce students to the techniques employed by experienced IT users, and encourage critical and discerning use of information technology. Actual instruction in how to use particular software packages is tailored to the individual student, partly through reliance on other campus resources such as workshops hosted by the IRT and partly through personal or small group instruction provided by the instructor of the course. The cumulative effect is to produce more independent and savvy IT users.

Student learning has demonstrably benefited from this arrangement. Although we are still waiting to see if students are better able to apply their IT skills in their subsequent graduate courses, exit examinations administered in HIST501 indicate improved ability using the software and techniques introduced in the course, even among students with very little prior IT experience. Furthermore, student evaluations and informal discussion reveal much more satisfaction with HIST501—and far fewer complaints. As an additional benefit, many students either develop viable thesis topics much earlier in their graduate careers than had previously been the case, or at least learn why certain topics are not practical (excessive breadth, lack of primary sources, foreign language requirements for research, etc.).

\section{Remaining Challenges}

Although most students report far more satisfaction with the course, those with the most limited IT background still express frustration and complain that even with additional help they were not able to master the software used in the course or apply the techniques presented when working on their own. Furthermore, the quality of instruction provided by IRT has proven to be uneven, shifting more of this respons ibility to the instructor of the course. The greatest challenge will probably prove to be meeting the needs of students without overburdening the faculty who volunteer to teach HIST501. In order to allow the restructuring I have undertaken, course enrollment caps were lowered (to eight students). While our graduate program is still young, enrollment limited, and administration's support strong, these small classes are viable. Should the program grow, as we hope, or budget constraints preclude such small classes, the ability of the faculty instructor to meet the needs of the students could be compromised.

\section{Plans for the Future}

To address the problems of instructor workload and dissatisfaction among students with limited technological backgrounds, in future iterations of the course I plan to pare down the content as much as possible while still honoring the intent of the course: to provide educators and those seeking to pursue further study or employment in history with a working knowledge of IT tools and applications that can enhance their teaching and research. To do so, I plan to follow up with students who have completed the course in order to find out what information technology covered by HIST501 they have actually used in other graduate courses, in their broader research, or in the ir own teaching. Preliminary discussions with students and other faculty indicate that eliminating the quantitative and statistical section of the course might be feasible, as few if any students who did not enter the program with a strong background in statistics incorporate quantitative analysis into their other coursework or their theses. Finally, I plan to recommend that the Department of History redouble its efforts to more fully integrate information techno logy into all graduate courses, to reinforce and expand fluency with technology beyond what can be accomplished in a single IT class (Talbot Bielefeldt, 2000). 


\section{Conclusions and Recommendations}

Based upon my experience with HIST501: Information Technology and the Historical Profession, I can recommend the following to instructors who teach IT to a non-technical audience with limited or varying experience with information technology:

- Orient learning around a project, preferably a project that is integral to students' broader course of study.

- Teach specific IT tools and techniques through tasks that contribute to the completion of the larger project.

- Avoid teaching the particulars of hardware and software in isolation from the completion of the larger project.

- Provide or arrange individual assistance for IT novices who need extra help rather than slowing the class to the speed of the least experienced student.

- Require a journal discussing all activities-even those not ultimately used in the thesis proposal—both for assessment and for students' future reference.

By learning information technology tools and techniques through the completion an historical project, devoting class time to discussion of techniques for solving problems, and learning the details using particular hardware or software on their own or through individual tutoring, students with widely divergent IT experience learned more, expressed more satisfaction with the course, and grew to be more enthusiastic and independent users of information technology.

\section{References}

Bielefeldt, Talbot (2000). Information Technology in Teacher Education: A Closer Look. Research Paper: Staying Connected with Professional Development. Connecting @ the Crossroads, NECC 2000: National Educational Computing Conference Proceedings (Atlanta, GA, June 26-28, 2000). Persistent link: http://search.epnet.com/direct.asp?an=ED444451\&db=eric\&tg=AN.

Information Literacy: Competency Standards for Higher Education (2001). Teacher Librarian, 28.3, 16-22. Persistent link: http://search.epnet.com/direct.asp?an=EJ628275\&db=eric\&tg=AN.

Kasowitz-Scheer, Abby, and Michael Pasqualoni (2002). Information Literacy Instruction in Higher Education: Trends and Issues. ERIC Digest. Syracuse, NY: ERIC Clearinghouse on Information and Technology. Persistent link: http://search.epnet.com/direct.asp?an=ED465375\&db=eric\&tg=AN.

Massey-Burzio, Virginia (1999). The Rush to Technology: A View from the Humanists. Library Trends, 47.4: 620-639. Persis tent link: http://search.epnet.com/direct.asp?an=EJ591549\&db=eric\&tg=AN.

Working Toward the Future with Our Children: The Education Technology Plan for New Jersey (2000). Retrieved 30 December 2002 from the World Wide Web http://www.state.nj.us/njded/techno/state plan.htm

Yildirim, Soner (2000). Effects of an Educational Computing Course on Preservice and Inservice Teachers: A Discussion and Analysis of Attitudes and Use. Journal of Research on Computing in Education, 32.4, 479-496. Persistent link: http://search.epnet.com/direct.asp?an=EJ606844\&db=eric\&tg=AN. 
HIST501 Information Technology and the Historical Profession

Spring 2003 - Syllabus

\section{Course Description}

This course introduces students to the uses of information technology as it applies to historical research and teaching, including online research, the digitization of physical resources, the manipulation of data, the construction of web sites, and live presentation. In order to learn useful hardware, software, tools, and techniques in the context of your career as an historian, over the duration of this course you will complete a project: a mock (or, hopefully, preliminary) proposal for an MA thesis. Accordingly, the course is divided into three sections: research and the acquisition of information, organization and manipulation of data, and the presentation of research findings. Through the production of a thesis proposal, students will learn the use of the hardware, software, and techniques necessary to successful conduct a modern research program. You will also find much of what you do in this course helpful in your teaching, particularly web development and live presentation.

\section{Week 01: Introduction}

Begin exploring topics of interest

Week 02: Acquiring Information: Library resources (Meet in Library; presentation by R. Kearney) Narrow and develop topic of interest; formulate the problem

\section{Week 03: Acquiring Information: Other online resources}

Continue work from last week. Conduct online and library research. Create a preliminary bibliography.

\section{Week 04: Acquiring Information: Gathering and digitizing physical information}

Consider what physical information (manuscripts, video or photographs of places, interviews, etc.) might be useful for your research interest. Locate these resources and make arrangements for their digitization.

\section{Week 05: Manipulating Information: Organizing your bibliography}

Enter your preliminary bibliography into the bibliographic software of your choice. Locate a data-rich source related to your proposal.

\section{Week 06: Manipulating Information: Storing, organizing, and retrieving information}

Determine how databases and/or spreadsheets might help you to organize information you are gathering for your proposal.

\section{Week 07: Manipulating Information: Quantitative approaches to history}

Decide what quantitative approach would be most applicable to your problem and execute it.

\section{Week 08: Presenting Information: Editing images, sound, and video}

Explore how images, audio, and sound could enliven your proposal. Strive for genuine enhancement through integration of multimedia; do not just "make it pretty." Begin preparing the images, audio, and/or video you collected earlier for inclusion in your presentation and web site.

\section{Week 09: Presenting Information: Live presentation}

Determine how you can most effectively "sell" your project. Your audience is receptive to your ideas but mildly skeptical. Begin composing a PowerPoint presentation (finish it over the next few weeks, perhaps in conjunction with the construction of your website, as some resources may be shared between the two).

\section{Week 10: Presenting Information: Basic website creation}

Repeat the last two weeks' exercises, but this time with the production of a web site in mind. How will your web site differ from your presentation? Assemble materials you want to include in your website. Begin composing text for your website.

Week 11: Presenting Information: Principles of good web design

Determine the most effective structure for your website and begin putting together the pieces you have assembled. Visit http://www.websitesthatsuck.com.

\section{Week 12: Presenting Information: Adding audio and video to websites}

Consider how you can enhance your website through the inclusion of multimedia. Reconsider the caveats discussed in Week Eight.

\section{Week 13: Presenting Information: Advanced web applications and techniques}

Consider what advanced web applications (Flash, streaming audio/video, JavaScript, etc.) would enhance your web site. Look around on the internet for websites that do things that you would like to imitate, and attempt to determine how that enhancement was accomplished (bring examples to class for discussion, whether or not you can "reverse-engineer" the site on your own). Continue constructing your web site.

Week 14: Student presentations; discussion and critique of student websites

Week 15: Student presentations; discussion and critique of student websites

Figure 1: HIST501 Syllabus 
HIST501 Information Technology and the Historical Profession Spring 2003 - Assignment Details

\section{Reading}

This course requires familiarity with both print and web resources concerning any hardware, software, and techniques we will utilize. Some reading will be required as you prepare you thesis proposal as well.

\section{Journal}

Your journal serves as both a means for me to monitor your learning in the class and a personal reference as you begin to employ IT tools and techniques in this class and beyond. Concerning your journal as a learning log, I would suggest keeping a "double entry journal," where you first take (or transcribe) notes from lectures, discussions, and readings, then comment and reflect on these notes at a later time. Your journal is also where you will develop ideas for your research proposal. Early in the semester, you should select and develop a research topic. Next, you will conduct preliminary research using the tools learned in this course to explore the feasibility of the project you have in mind and underpin your proposal. Students will then employ at least two of the programs for data manipulation discussed in class (this will require at least one data-rich source, something to keep in mind as you conduct your research). Finally, students will prepare a thesis proposal, a web site, and a live presentation (see below), and share these with the class. Grading for the journal will be based primarily upon your write-up of the tools employed in research, data manipulation/organization, and presentation, secondarily upon the thoroughness of your research and bibliogr aphy .

\section{Thesis Proposal}

Following the Department of History Thesis Proposal Format, students will prepare a 3-5 page thesis proposal, supporting bibliography, and plan of research.

\section{Live Presentation}

Students will "sell" their thesis proposal in a 15-20 minute live presentation using MS PowerPoint and a data projector. Again, refer to the department guidelines for the thesis presentation when planning this assignment. This presentation should incorporate still images plus at least three of the following: animation, diagrams, audio, video.

\section{Website}

Each student should create a website using Macromedia DreamWeaver which not only incorporates multimedia from his/her PowerPoint presentation but also presents further information from his/her thesis proposal, links to relevant websites, images, documents, audio, and video. One advanced web technique discussed in class should be employed, while potential expansions using the other techniques should be discussed in the journal. Design of the site should be discussed and defended in the journal; why did you create the site as you did?

\section{Final Exam}

A final exam testing the knowledge of a representative sample of hardware, software, and techniques discussed in class will be administered.

\section{Participation}

Students are expected to attend class and participate in all activities and discussions.

\section{Figure 2: HIST501 Assignment Details}

